\title{
Rancang Bangun DATA MANIA \\ sebagai Multimedia Interaktif Data Keselamatan \\ Bahan Kimia Berbasis Augmented Reality
}

\section{The Design of DATA MANIA as Augmented Reality Based Interactive Multimedia on Chemical Safety Data}

\author{
A Pradipta ${ }^{1^{*}}$, M Aziz $^{2}$, I A Fajri ${ }^{3}$ and M Khair ${ }^{1}$ \\ ${ }^{1}$ Pendidikan Kimia, Universitas Negeri Padang, Jl. Prof. Dr. Hamka, Air Tawar Barat, \\ Padang Utara, Sumatera Barat, Indonesia 25171 \\ ${ }^{2}$ Pendidikan Teknik Informatika, Universitas Negeri Padang, Jl. Prof. Dr. Hamka, Air Tawar Barat, \\ Padang Utara, Sumatera Barat, Indonesia 25171 \\ ${ }^{3}$ Kimia, Universitas Negeri Padang, Jl. Prof. Dr. Hamka, Air Tawar Barat, \\ Padang Utara, Sumatera Barat, Indonesia 25171
}

*arunapradipta22@gmail.com

\section{ARTICLE INFO}

Received 03 January 2020

Revised 22 January 2020

Published 18 May 2020

\section{ABSTRACT}

The Design of this Interactive Multimedia is motivated by the increasing number of work accidents that occur in chemical laboratories due to students lack of knowledge of properties about the properties of chemicals and work safety in the laboratory. Based on data obtained from research conducted at the existing SMAN in Temanggung sub-district, it was concluded that the level of student knowledge regarding the aspects of chemicals and work safety in the laboratory was not evenly distributed. Methods in making this application include collecting literature, designing and developing applications, trials and publications. The results of making this application can be used for practician especially students in experiments in chemical laboratories. With this interactive multimedia the Chemical Safety Data based on Augmented Reality can provide convenience in obtaining chemical information and can reduce the risk of work accidents in the Chemistry Laboratory.

\section{KEYWORDS}

Interactive Multimedia, Chemistry Laboratory, Chemical Safety Data, Augmented Reality

\begin{abstract}
ABSTRAK
Pembuatan Multimedia Interaktif ini dilatarbelakangi oleh meningkatnya jumlah kecelakaan kerja yang terjadi di laboratorium kimia akibat rendahnya pengetahuan siswa tentang sifat-sifat bahan kimia dan keselamatan kerja di laboratorium. Berdasarkan data yang diperoleh dari penelitian yang dilakukan pada SMAN yang ada di kecamatan Temanggung, didapatkan kesimpulan bahwa tingkat pengetahuan siswa mengenai aspek bahan kimia dan keselamatan kerja di laboratorium masih belum merata. Metode dalam pembuatan aplikasi ini diantaranya mengumpulkan literatur, merancang dan mengembangkan aplikasi, uji coba dan publikasi. Hasil dari pembuatan aplikasi ini telah dapat digunakan bagi praktikan khususnya siswa dalam praktikum di laboratorium kimia. Dengan adanya multimedia interaktif Data Keselamatan Bahan Kimia berbasis Augmented Reality ini dapat memberikan kemudahan dalam memperoleh informasi bahan kimia dan dapat mengurangi risiko kecelakaan kerja di Laboratorium Kimia.
\end{abstract}

\section{KATA KUNCI}

Multimedia Interaktif, Laboratorium Kimia, Data Keselamatan Bahan Kimia, Augmented Reality 


\section{PENDAHULUAN}

Sumber kecelakaan terbesar bekerja di laboratorium kimia berasal dari bahan-bahan kimia dan faktor manusia. Pemahaman jenis, sifat, dan cara menanggulangi bahan kimia sangat diperlukan oleh praktikan di laboratorium ${ }^{[1]}$. Pemahaman jenis, sifat, dan cara menanggulangi bahan kimia sangat diperlukan oleh praktikan di laboratorium ${ }^{[2]}$.

Bekal pengetahuan Bahan Kimia perlu dimiliki siswa mengingat bahan kimia memiliki potensi untuk menimbulkan bahaya, baik terhadap kesehatan maupun dapat menimbulkan bahaya kecelakaan. Hal ini dapat dipahami karena bahan kimia dapat memiliki tipe reaktivitas kimia tertentu dan juga dapat memiliki sifat mudah terbakar ${ }^{[3]}$.

Untuk dapat mendukung jaminan kesehatan dan keselamatan kerja maka para pelaksana yang bekerja di laboratorium termasuk mahasiswa harus mengetahui dan memiliki pengetahuan serta keterampilan untuk menangani bahan kimia khususnya dari segi potensi bahaya yang mungkin ditimbulkan ${ }^{[4]}$. Informasi atau pengetahuan yang harus diketahui pelaksana di laboratorium kimia yang diberikan oleh Phifer salah satunya adalah informasi tentang Material Safety Data Sheet (MSDS) ${ }^{[5]}$.

Berdasarkan hasil penelitian oleh Hidayati melalui uji tingkat pengetahuan keselamatan kerja di laboratorium kimia untuk peserta didik kelas XI IPA Semester 1 di seluruh SMAN Kecamatan Temanggung, Kabupaten Temanggung, Jawa Tengah, didapatkan hasil dari SMAN yang ada di seluruh Kecamatan Temanggung, Jawa Tengah, yang terdiri dari SMAN 1 Temanggung, SMAN 2 Temanggung, dan SMAN 3 Temanggung. Peneliti mendapatkan hasil bahwa dari tingkat pengetahuan kerja siswa di laboratorium pada aspek pengetahuan bahan kimia dan sifat-sifatnya memiliki rata-rata $56,67 \%$, serta berdasarkan aspek pengetahuan pada pencegahan dan P3K di laboratorium sebesar 45,87\% dari jumlah keseluruhan siswa kelas XI di SMAN Kecamatan Temanggung. Dari data ini, dapat disimpulkan bahwa tingkat pengetahuan siswa pada aspek bahan kimia dan sifat-sifatnya serta pencegahan dan P3K di laboratorium termasuk dalam kategori sedang. Dengan kata lain, pengetahuan siswa tentang bahan kimia dan keselamatan kerja di laboratorium masih belum merata, hal ini dikarenakan belum adanya kebijakan kurikulum yang mengatur standar kompetensi, seperti dalam Peraturan Menteri Pendidikan Nasional nomor 22 tahun 2006 yang tidak mencantumkan pengetahuan laboratorium baik pengetahuan ataupun keselamatan kerja yang mendasari berlangsungnya praktikum, padahal pengetahuan ini yang nantinya akan menjadi bekal bagi siswa untuk melaksanakan praktikum di laboratorium kimia ${ }^{[6]}$.

Dari permasalahan di atas, penulis merancang aplikasi DATA MANIA sebagai inovasi multimedia interaktif data keselamatan bahan kimia berbasis Augmented Reality dengan menggunakan kode CAS Number yang bersifat universal dan terintegrasi dengan $Q R$-Code sebagai maker-nya, sehingga aplikasi ini dapat diakses oleh siapapun, kapanpun dan dimanapun. Dalam Aplikasi ini tersedia berbagai fitur media seperti teks, gambar, animasi 3D serta audio yang dapat memudahkan siswa dalam memahami informasi terkait data keselamatan bahan kimia. Selain itu dengan adanya berbagai fitur yang tersedia dapat menarik minat siswa untuk mempelajarinya dan mengurangi risiko terjadinya kecelakaan kerja di laboratorium.

\section{METODE}

Model pengembangan dalam penelitian ini mengikuti alur dari sivasailam Thiagarajan, Dorothy S. Semmel, dan Melvyn I. Semmel (1974). Model Pengembangan 4-D tahap utamanya yaitu Define, Design, Develop, dan Disseminate atau diadoptasikan menjadi model 4-P, yaitu tahap pendefinisian, perancangan, pengembangan, dan penyebaran ${ }^{[7]}$.

\subsection{Prosedur Pengembangan}

Pada tahap define dilakukan penelitian pendahuluan melalui lima analisis yaitu: front end analysis (analisis ujung depan), learner analysis (analisis siswa), task analysis (analisis tugas), concept analysis (analisis konsep) dan specifying instructional objectives (perumusan tujuan pembelajaran). Instrumen yang digunakan pada tahap ini berupa angket yang diberikan kepada 3 orang guru kimia SMA dan 30 orang siswa SMA Negeri 1 Bukittinggi.

Adapun pada tahap design terdapat beberapa langkah dalam perancangan dan pemodelan aplikasi DATA MANIA adalah sebagai berikut:

1. Merancang Tampilan dan Sajian Menu Aplikasi

Membuat Gambaran Rancangan Tampilan dan Sajian Menu dalam Aplikasi DATA MANIA.

2. Membuat objek 3D senyawa bahan Kimia

Mendesain Objek 3D Senyawa Bahan Kimia dengan menggunakan Aplikasi 3D Modeling.

3. Membuat $Q R$-Code dan CAS Number

Membuat marker berupa $Q R$-Code dengan menggunakan $Q R$-Code Generator dan membuat marker berupa nomor CAS Number yang spesifik untuk setiap bahan kimia.

4. Upload dan Download

Meng-upload QR-Code ke Website Vuvoria dan menambahkan CAS Number yang berfungsi agar maker dapat terdeteksi oleh aplikasi Game Engine.

5. Merekam Audio

Merekam suara untuk sajian audio pada aplikasi DATA MANIA

6. Mendesain Tampilan

Membuat tampilan program dan sajian menu aplikasi.

7. Menggabungkan Keseluruhan

Menggabungkan objek, marker, sekaligus menambahkan teks, gambar, serta audio informasi data keselamatan bahan menggunakan aplikasi Game Engine.

8. Membuat Apk

Menjadikan Aplikasi ke dalam format apk agar dapat dijalankan pada Android/ Smartphone. 
Pada tahap develop, dilakukan uji coba penerapan aplikasi DATA MANIA yang bertempat di SMA Negeri 1 Bukittinggi dengan instrumen yang digunakan berupa angket. Angket praktikalitas diberikan kepada 3 orang guru kimia SMA Negeri 1 Bukittinggi dan 30 orang siswa SMA Negeri 1 Bukittinggi.

Angket praktikalitas yang digunakan terdiri dari beberapa aspek, diantaranya aspek fungsi aplikasi, aspek desain aplikasi, aspek kemudahan penggunaan dan kesesuaian penggunaan aplikasi.

Pada tahap disseminate, telah dilakukan Sosialisasi Aplikasi kepada Majelis Guru Mata Pelajaran Kimia Kabupaten Agam dan Majelis Guru SMA Negeri 1 Bukittinggi yang bertujuan agar Aplikasi ini dapat diterapkan menjadi media pembelajaran interaktif bagi peserta didik yang dapat memudahkan peserta didik memahami data keselamatan bahan kimia sebelum melakukan praktikum di Laboratorium Kimia Sekolah. Aplikasi DATA MANIA ini juga telah terdaftar Hak Ciptanya melalui HKI (Hak Kekayaan Intelektual) dengan nomor Kode Ciptaan EC00201944894 dan termasuk dalam jenis Ciptaan Program Komputer. Pendaftaran HKI ini bertujuan untuk memperluas penyebaran Aplikasi agar dapat di-upload ke Google Play Store sehingga dapat dijangkau oleh seluruh masyarakat khususnya praktisi yang bekerja di laboratorium kimia.

Data Hasil Uji Praktikalitas yang diperoleh, dianalisis menggunakan rumus persentase dari pilihan jawaban yang diberikan oleh guru dan siswa. Kemudian diperoleh hasil data dengan tampilan persentase melalui diagram donut seperti pada Gambar 5 yang ditampilkan.

\section{HASIL DAN DISKUSI}

\subsection{Tampilan Aplikasi}

Aplikasi DATA MANIA sudah dapat digunakan. Berikut adalah logo aplikasi yang dibuat. DATA MANIA merupakan nama aplikasi yang merupakan singkatan dari Data Keselamatan Bahan Kimia. Gambar 1 merupakan logo dari aplikasi DATA MANIA. Setelah itu Gambar 2, Gambar 3 dan Gambar 4 terlihat tampilan menu aplikasi, mulai dari tampilan menu awal hingga menu setelah scanning bahan dari aplikasi ini.

Keunggulan dari aplikasi DATA MANIA terletak pada tampilan media yang interaktif yang disajikan, dengan adanya tampilan informasi berupa teks, suara, gambar, dan animasi 3D sehingga siswa akan lebih mudah memahami data keselamatan bahan kimia dibandingkan harus membaca lembar data keselamatan bahan lainnya yang berupa teks yang panjang dan terkadang juga sulit untuk dipahami.

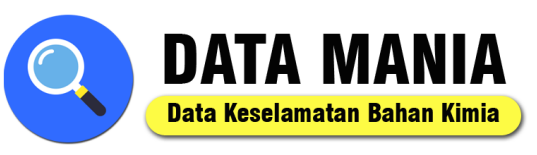

Gambar 1. Logo Aplikasi DATA MANIA.

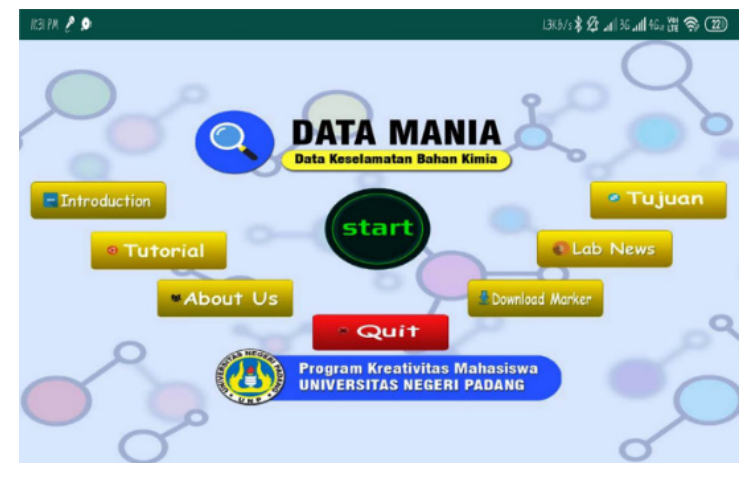

Gambar 2. Tampilan Menu Awal.

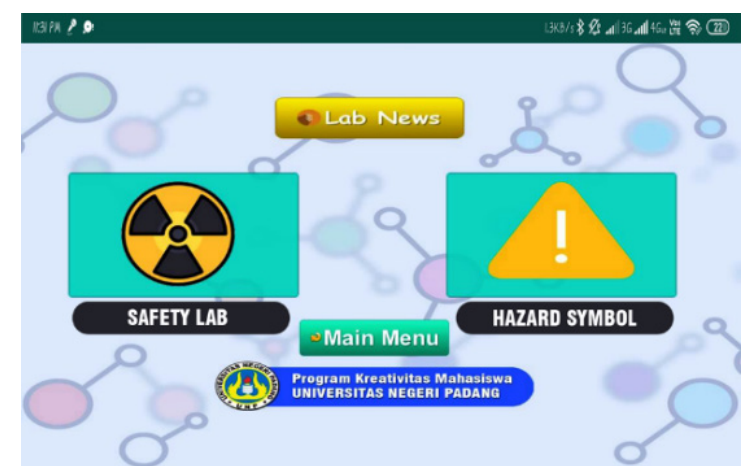

Gambar 3. Tampilan Menu Lab News.

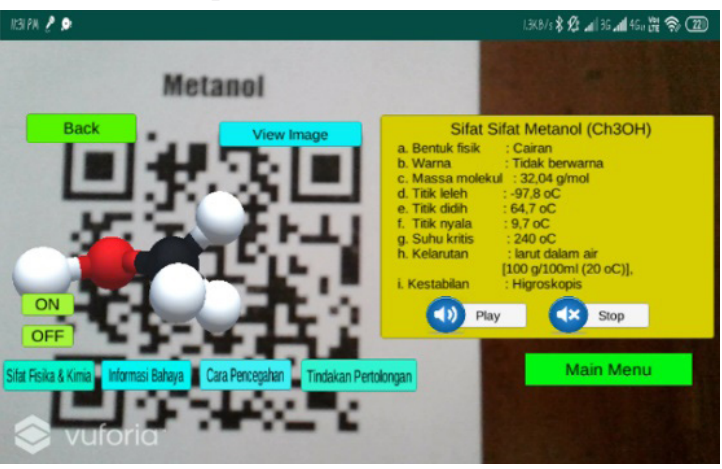

Gambar 4. Tampilan Menu Scanning Barcode.

\subsection{Hasil dan Pembahasan}

Pengembangan Produk Multimedia Interaktif DATA MANIA (Data Keselamatan Bahan Kimia) berbasis Augmented Reality menghasilkan aplikasi edukasi berbasis android yang dapat digunakan pada smartphone sebagai media pembelajaran untuk memudahkan peserta didik dalam memahami sifat, karakteristik, kegunaan dan cara penyimpanan bahan kimia yang ada di laboratorium kimia sekolah sebelum melakukan kegiatan praktikum. Aplikasi Multimedia Interaktif ini memiliki beberapa fitur diantaranya teks, gambar, audio dan animasi 3D. Menurut Suyitno (2016) media interaktif yang berwujud teks, visual, dan simulasi dapat membantu siswa mendapatkan pengetahuan lebih, pemahaman konsep yang mendalam, serta mengetahui aplikasi ilmu yang dipelajari ${ }^{[7]}$.

Hal ini sesuai dengan Analisa hasil data angket praktikalitas yang telah diberikan kepada 3 orang Guru Kimia dan 20 orang peserta didik di SMA Negeri 1 Bukittinggi dengan beberapa poin dan indikator yang ditanyakan, diantaranya seberapa 

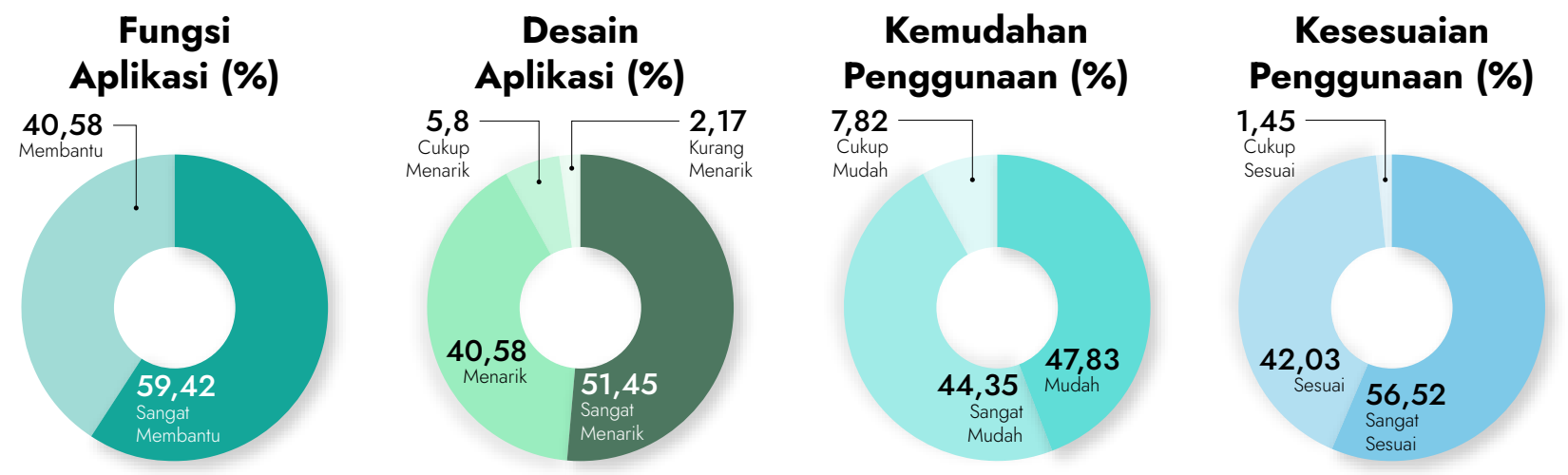

Gambar 5. Persentase Fungsi Aplikasi, Desain Aplikasi, Kemudahan Penggunaan dan Kesesuaian Penggunaan.

membantukah fungsi aplikasi bagi mereka; seberapa menarik desain aplikasi menurut mereka; seberapa mudah mereka dalam menggunakan aplikasi, dan seberapa sesuai penggunaan fitur yang ada. Diperoleh hasil data pada aspek fungsi aplikasi yaitu sebanyak $59,42 \%$ peserta didik menyatakan sangat membantu dan 40,58\% menyatakan sudah membantu. Selanjutnya dari hasil data pada aspek tampilan desain aplikasi, 51,4\% peserta didik menyatakan sangat menarik 40,58\% menyatakan menarik, 5,8\% peserta didik menyatakan cukup menarik, dan $2,17 \%$ peserta didik menyatakan kurang menarik. Kemudian dari hasil data angket praktikalitas pada aspek kemudahan dalam penggunaan, 44,35\% peserta didik menyatakan sangat mudah, $47,83 \%$ peserta didik menyatakan mudah, dan 7,82\% peserta didik menyatakan cukup mudah. Selain itu dari hasil data angket praktikalitas pada aspek kesesuaian fitur dalam program aplikasi didapatkan hasil $56,52 \%$ peserta didik menyatakan sangat sesuai, 42,03\% menyatakan sesuai, dan $1,45 \%$ peserta didik menyatakan cukup sesuai. Melalui analisa data hasil angket praktikalitas ini dapat terlihat bahwa lebih dari 50\% responden menyatakan sangat baik dari segi fungsi, desain, dan kesesuaian program aplikasi, namun dari segi kemudahan aplikasi berdasarkan hasil data menunjukkan kurang dari 50\% yang menyatakan sangat mudah sehingga masih perlu adanya penyempurnaan lebih lanjut, agar program aplikasi dapat digunakan oleh semua kalangan baik siswa, mahasiswa ataupun praktisi lainnya yang bekerja di laboratorium kimia. Uraian lengkap persentase hasil analisa angket praktikalitas aplikasi dapat dilihat pada Donut Chart yang ada pada Gambar 5.

\section{SIMPULAN}

Dengan memperhatikan hasil uji coba, aplikasi ini memiliki keunggulan terbesar dalam hal fungsi. Responden merasa aplikasi ini memiliki fungsi yang bermanfaat bagi mereka. Sedangkan hal yang masih perlu untuk dikembangkan adalah tampilan desain aplikasi. Responden masih ada yang menilai kurang menarik dari segi tampilan desain, dan dalam saran pada angket juga masih banyak yang mengatakan kalau teks informasi masih terlalu kecil font nya dan sebaiknya ukuran huruf agak diperbesar agar mudah terbaca.
Berdasarkan Analisa Uji Evaluasi aplikasi, maka dapat disimpulkan praktikan yang bekerja di laboratorium khususnya peserta didik sudah dapat lebih mudah memahami data keselamatan bahan kimia dengan sajian aplikasi berupa multimedia yang interaktif dan menarik. Harapan kami aplikasi DATA MANIA ini dapat dimanfaatkan oleh orang banyak khususnya untuk semua praktisi yang bekerja di laboratorium, sehingga dengan adanya aplikasi ini dapat memudahkan praktisi dalam memahami data keselamatan bahan kimia dan mengurangi risiko terjadinya kecelakaan kerja di laboratorium kimia.

\section{REFERENSI}

1. Lasia K. Analisis Pengetahuan Mahasiswa Tentang Dampak Penggunaan Bahan Kimia Dalam Praktikum Kimia Organik Terhadap Kesehatan. Semin Nas FMIPA UNDIKSHA III 2013;

2. Muhtaridi. Keselamatan Kerja Di Laboratorium. Makal dalam Pelatih laboran di Makasar 2011;

3. Tahir I; Sugiharto E. Pengelolaan Dan Implementasi Material Safety Data Sheet (MSDS) Pada Riset Mahasiswa Untuk Mendukung Kesehatan Dan Keselamatan Kerja Di Laboratorium. 2002;

4. Crisp. Safety in the School of Chemical Engineering and Industrial Chemistry. New South Wales: Safety Officer CEIC; 1996.

5. Phifer R., Lowry G., Ashbrook P, Peter E. Laboratory Waste Management, A Guidebook. Washington: 1994.

6. Hidayati W. Tingkat Pengetahuan Keselamatan Kerja di Laboratorium Kimia Peserta Didik Kelas XI IPA Semester 1 SMAN di Kecamatan Temanggung Kabupaten Temanggung Jawa Tengah. Univ. Islam Negeri Sunan Kalijaga 2010;

7. Suyitno S. Pengembangan Multimedia Interaktif Pengukuran Teknik untuk Meningkatkan Hasil Belajar Siswa SMK. I Pendidik Teknol dan Kejuru 2016;23(1):101. 